\title{
Student Course Evaluations In Traditional And Blended Courses: A Case Study
}

Gadis Nowell, Howard University, USA

\begin{abstract}
It is generally held that blended learning is gaining acceptance and being adopted at college campuses throughout the U.S. Accompanying this trend has been an expansion of the research efforts in this area. These efforts have been guided mainly by the five pillars of the Sloan Consortium Quality Framework (Sloan-C) and two large questions. One question is, "Is blended learning better than other learning environments?" In this study, this question was examined from the perspective of the Sloan-C's student satisfaction pillar. The research question was stated as follows: "Is the level of student course satisfaction generated by blended learning higher than that which is generated by traditional face-to-face classroom learning?" The results of this study revealed "no differences" between blended and traditional learning on the student course satisfaction variable. In this regard, it is important to note that this finding of "no differences" is consistent with the existing research findings on student learning effectiveness as well. Given this combined evidential pattern the following question is relevant and has implications for future research efforts in this area: "Within the context of cost/benefit analysis, why should an institution invest the additional resources needed to effectively implement a blended format when, in accordance with the existing research evidence, there is little or no net benefit in terms of its impact on students; i.e., either in terms of student satisfaction or student learning?".
\end{abstract}

Keywords: Blended Learning; Hybrid Learning; Distance Learning; Online learning

\section{INTRODUCTION}

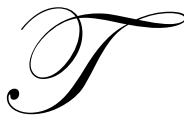

he definitions for blended learning vary considerably. Blended learning, for instance, is also known as hybrid learning, mixed mode learning, flexible learning, etc. A significant group of educational scholars, on the other hand, seem to prefer defining blended as simply the combination of online (mostly asynchronous) learning with face-to-face learning environments. This definition emerged from workshops sponsored by the Sloan-Consortium and can be more formally stated as follows: "Blended courses integrate online with face-to-face instruction in a planned, pedagogically valuable manner". This study adheres to this definition. In the courses used, for instance, students spent one day in a traditional face-to-face lecture-oriented classroom and one-day online (with no scheduled class meeting).

While definitions vary, the trend toward the adoption of blended learning is quite clear. As noted by Vignare and others, blended learning is gaining acceptance and being adopted at college campuses throughout the U.S. Accompanying this trend is an expansion of research efforts in this area as well; and according to Vignare, these efforts have been guided by the five pillars of the Sloan Consortium Quality Framework (Sloan-C). Vignare and Moore have described the Sloan-C pillars as follows:

\section{Cost Effectiveness and Institutional Commitment}

The cost effectiveness pillar includes issues like institutional commitment as evidenced through infrastructure, marketing, business strategies, scalability and partnerships. Within these parameters is an underlying constant that fully online and blended learning continually meet cost effective standards. 
Access

This pillar includes technical, academic and administrative services (infrastructure), learning resources, pre-course access and readiness, appropriate program information, and program and course variety ..... Under technical, academic and administrative services falls the issue of making sure all students have equal access to online learning. For the most part, access is addressed at an institutional level, and it is clear that the mission of the institution impacts its willingness to support blended learning.

\section{Learning Effectiveness}

In accordance with this pillar, the appropriate measure for learning effectiveness is to make sure the quality of online learning is as good as the quality of classroom learning; i.e., as indicated by such measures as grades, dropout rates, withdrawals and failures.

\section{Faculty Satisfaction}

Faculty satisfaction factors include administrative and technical support, quality control, institutional rewards, research opportunities, access to new populations of students and participation in interactive learning communities.

\section{Student Satisfaction}

The student satisfaction pillar includes student services, technology infrastructure and support, interaction with faculty and other students, and course/learning outcomes which match or exceed expectations.

Along with the guiding influence of Sloan-C, the area's research efforts have also been guided by, as Vignare phrases it, "two large questions"; i.e., "Is blended learning effective as measured through traditional methods of grades, course completion, retention, and graduation rates?" and, "Is blended learning better than other learning environments?" The research evidence relating to these questions is weak and inconclusive in several areas, per a review of the literature by Vignare. Therefore, Vignare concluded that more research is needed so as to bring greater clarity on the issues that underlie the questions, especially in the Sloan-C pillars relating to faculty satisfaction, student satisfaction, and access (p. 56). This study is a response to this recommendation and will focus on the "student satisfaction" pillar within the framework.

There are a large number of blended and online learning providers that collect data on student course satisfaction. Of this set, the most extensive database is that of Dziuban et al. These investigators collected nearly 200,000 student surveys over a seven year period, and the findings from these surveys have been quite similar, i.e., they consistently show that high levels of student satisfaction can, under certain circumstances, be achieved with blended and online learning. What these findings do not show, however, is that the level of satisfaction achieved with blended learning is different from that of traditional face-to-face classroom learning. This study focuses on this gap in the research evidence; i.e., as it pertains to the larger question of whether blended learning is better than other learning environments. In proceeding, our efforts will be guided by the following question: "Is the level of student course satisfaction generated by blended learning higher than that which is generated by traditional face-to-face classroom learning?" This question refines the larger question via specifying that, in this study, the "other" learning environment is a "traditional classroom environment", as opposed to some other environment; e.g., the fully online environment.

To our knowledge, our research question has not been directly examined in the literature, especially as it relates to blended learning. Therefore, it is our contention that, via its findings, this study will serve to advance our understanding of the issues at hand by: 1) establishing a baseline for future investigations of the guiding question, 2) contributing to the ongoing discussion and debate about the relative effectiveness of blended and traditional learning in terms of meeting and shaping learners' expectations and experiences within the classroom, and 3) contributing to the discussion relating to cost effectiveness when contemplating the adoption of a blended learning format within an institution. 


\section{METHODOLOGY}

\section{The Sample}

This study was conducted within Howard University's School of Business. It encompassed all sections of an introductory management course taught in Fall 2007. There were seven sections in all. Two of these used the blended learning model and were taught by the same instructor. The remaining five sections used the traditional face-to-face learning model where lecturing was the main pedagogy. Except for the blended courses in this study, there were no other such courses (or fully online courses) offered in the school during the period of this study, in that the school had not formally embraced this learning format at the time.

The blended courses were not "selected" by students because they were not coded as blended in the registration materials. The students, therefore, signed-up for what they thought would be traditional lecture courses. They only learned about the blended format on the first day of class. Here the point is that both the blended and traditional students entered their courses with similar classroom experiences and expectations. They all had traditional learning backgrounds and expectations about what would transpire in such courses.

The samples were similar in other ways as well; i.e., they were all full-time second year sophomores who entered the university directly out of high school, they had no prior experiences with online courses in high school or during their first year of matriculation at Howard, and they were also similar in terms of age (18-21) and mixed in terms of sex (approximately 60/40 females). While the blended sample included all students in the school who were registered in blended courses, the traditional sample represented only a subset of the schools' other traditional courses. It was, therefore, a convenience sample. Moreover, the information available on this sample was restricted and quite limited; i.e., as compared to the blended sample.

\section{Database}

The data for this study came from a student course evaluation questionnaire. The questionnaire is administered twice a year; i.e., near the end of each semester. It is administered during the regular class periods. For the blended courses, it was administered during the regular class periods and "online" using the Blackboard Course Management system. Because of absences and tardiness on the day it was administered in the blended courses, the response rate was lower than that achieved with the online administration (60\% vs. $79 \%)$. The analysis which follows, therefore, is based on the students' online responses. Comparable online data were not available for the traditional sample. Instead, data were used from their "in-class responses"; and even here, we had access only to their mean scores.

The questionnaire itself is made up of ten structured questions and four open-ended essay questions. The structured questions are divided into two categories: Course Evaluation and Instructor Evaluation. The former encompasses the following evaluation criteria: effectiveness of course materials used, degree of learning in course, fairness of grading system of course as measure of student performance, appropriateness of difficulty of course for its level, and, overall evaluation of course. The latter encompasses: instructor's ability to communicate with students, instructor's interest in student learning, effectiveness of instructor's teaching methods, instructor's organization of course, and, overall performance of instructor as an educator. The open-ended inquiry used in this study was: To encourage continuation of what you found praiseworthy, please list any features that you particularly liked about this course/instructor. The open-ended inquiry was coded independently by two individuals and interrater reliability was 87 percent.

\section{RESULTS}

In Table-01, the results from our analysis of the 10 structured items included on the "student course evaluation questionnaire" are shown for the blended and traditional learning courses. Students rated each item on a 5 -point scale ( $5=$ very good; $4=$ good; $3=$ satisfactory; $2=$ poor; and 1=very poor) and the resulting "mean scores" are shown for each course. Unfortunately, tests of significance between the means could not be performed because the required data were not made available on students in the traditional course. 
Table 01: Blended and Traditional Learning

\begin{tabular}{lcc}
\hline \multicolumn{1}{l}{ Blended Course } & Traditional Course \\
\hline How would you rate the Course on: & & 3.20 \\
1. Effectiveness of course materials. & 3.38 & 2.80 \\
2. Degree of Learning in course & 3.17 & 3.20 \\
3. Fairness of Grading System & 3.24 & 3.20 \\
4. Difficulty of Course & 3.37 & 3.20 \\
5. Its Overall evaluation as a course & 3.13 & \\
& & \\
How would you rate the "Instructor" on: & & 3.40 \\
6. Ability to communicate with students & & 3.60 \\
7. Interest in student learning & 3.33 & 2.40 \\
8. Effectiveness of teaching methods & 3.43 & 3.60 \\
9. Organization of course & 3.03 & 3.00 \\
10. Overall performance as an instructor & 3.82 & \\
\hline
\end{tabular}

Table-01 shows that on 8 of the 10 evaluation criteria, the mean scores for the blended and traditional courses were within the same range; i.e., greater than 3.0, but less than 4.0 (items: 1,3,4 and 5 for course evaluation; items: 6,7,9 and 10 for instructor evaluation). On the questionnaire's rating scale of 1-5, these scores were within the "satisfactory" range. Therefore, within the context of their traditional classroom experiences and expectations, students in the blended and traditional courses rated them as being "satisfactory" with respect to course content and instructor performance (i.e., satisfactory instead of poor, good, or very good). The specific ratings were as follows for the blended and traditional courses, respectively:

Course Content: Effectiveness of course materials (3.38/3.20); Fairness of Grading System (3.24/3.20); Difficulty of Course (3.37/3.20); Overall evaluation of the course $(3.13 / 3.20)$

Instructor Performance: Ability to communicate with students (3.33/3.40); Interest in student learning (3.43/3.60); Organization of course (3.82/3.60); Overall performance as an instructor (3.38/3.00)

There were two exceptions to this pattern; i.e., "degree of learning" in the course evaluation section (item 2) and "effectiveness of teaching methods" in the instructor's evaluation section (item 8). For degree of learning", the blended course was assigned a "satisfactory" rating by its students (mean score of 3.17), whereas students in the traditional course gave it a "poor" rating (mean score of 2.80). This pattern was repeated for "effectiveness of teaching methods". Here the blended course was rated as "satisfactory" (mean score of 3.03), whereas the traditional course was again rated as "poor" (2.40). Do these results support the view that, in these two areas, the blended course generated better results than the traditional course?

One way of approaching this question would have been via a test of significance between the means. Unfortunately, the data needed to conduct such a test were not available because the information needed from traditional students was restricted. Data were available, however, on the blended students' responses to the following essay: "To encourage continuation of what you found praiseworthy, please list any features that you particularly liked about the course/instructor." Thus, to partially get around the mean test difficulty and thereby shed some light on the results, the responses to this essay question were examined for "themes". Here the intent was to gain some perspective on whether the course differences resulted from the unique features of the blended format or were simply generic in nature. Table-02 lists the themes identified, along with the percent of all respondents who mentioned each theme. 
Table-02: Themes from the Question: To encourage continuation of what you found praiseworthy, please list any features that you particularly liked about the course/instructor?

\begin{tabular}{lc}
\hline Themes & $\begin{array}{c}\text { \% of students in each } \\
\text { theme category }\end{array}$ \\
\hline 1. Liked the opportunity to earn bonus points as a way of improving my grade & 44 \\
2. The course and instructor were well organized & 18 \\
3. Liked the instructional method that deemphasized the use of lectures & 08 \\
4. Instructor was approachable, available, and interested in student learning & 08 \\
5. Instructor was fair in grading & 04 \\
6. Liked having online (24/7) access to course materials and information & 14 \\
7. Liked the online tests and quizzes & 12 \\
8. Liked having to spend only one day per week in class meetings & 04 \\
\hline
\end{tabular}

As shown, three of the eight themes identified were unique to the blended format; i.e., themes that one would associate only with blended learning. They were: Liked having online access to course materials and information (item 6); Liked the online tests and quizzes (item 7), and Liked having to spend only one day per week in class (item 8). The percent of students in each category were, respectively, $14 \%, 12 \%$, and $4 \%$. Needless to say, these results do not support the view that the higher scores of the blended course were due to its unique learning format (i.e., Table-01: the higher scores for "degree of learning in course" and "effectiveness of teaching methods"). Rather, it seems that the results had more to do with how the blended instructor organized the grading process with respect to providing opportunities for grade improvements via the acquisition of bonus points. This rationale is suggested by the dominant theme in Table-02; i.e., "Like the opportunity to earn bonus points as a way of improving grades". This theme was identified in $44 \%$ of the students' responses. The suggestions here are that the bonus strategy was perceived by most students as being an "effective teaching method" and because of it and their improved grades, their perception of having "learned more" was enhanced.

\section{DISCUSSION AND CONCLUSIONS}

Overall, then, our results indicate that the blended and traditional courses did not differ in terms of student satisfaction levels; i.e., students rated both courses as being "satisfactory", as opposed to "poor", "good", or "very good". Or, within the context of the question being examined in this study, the blended course did not generate better results than the traditional course. On the other hand, and from another perspective, it is important to point out that the results from this study are, indeed, consistent with the research findings on the Sloan-C's pillar of learning effectiveness. That is, the findings, while not conclusive, do support the view that blended learning is "at least as effective as" traditional learning in promoting learning effectiveness (e.g., course completion rates, program completion rates, graduation rates, grades, dropout rates, withdrawals, and failure rates).

The problem, however, is that none of this evidence support the view that blended learning, as opposed to traditional learning, generally produces higher levels of student course satisfaction and learning effectiveness. So, from our perspective, an important question is: "Within the context of cost/benefit analysis, why should an institution invest the additional resources needed to effectively implement a blended format when, in accordance with the existing research evidence, there is little or no "net benefit" in terms of its impact on students; i.e., either in terms of student satisfaction or student learning?" Here the implications are clear for those of us who advocate for the use of blended learning. We must make, via our research efforts, a stronger case for the blended format. We can do this by focusing significantly more of our efforts on ways to improve the format so that it does, indeed, produce better results than traditional learning; i.e., in the interrelated areas of student satisfaction and learning effectiveness. This type of action is necessary as a way of gaining the support of administrators with respect to their willingness to invest the additional scarce resources needed for an effective implementation of a blended format. Needless to say, such an investment is more likely to be made when there are expectations that the format will indeed produce net benefits for students; i.e., in the interrelated areas of learning effectiveness and student satisfaction. 


\section{REFERENCES}

1. Allen, I.E. \& Seaman, J. (2005). Growing by degrees: Online education in the United States, 2005. Needham, MA: Sloan-C.

2. Allen, I.E. \& Seaman, J. (2004). Entering the mainstream: The quality and extent of online education in the United States, 2003 and 2004. Needham, MA: Sloan-C.

3. Dziuban, C.D., Hartman, J., Juge, F., Moskal, P.D., \& Sorg, D. (2005). Blended learning enters the mainstream. In C.J. Bonk \& C. Graham (Eds.), Handbook of Blended Learning: Global perspectives, local designs (pp. 195-208). San Francisco, CA: Pfeiffer Publishing.

4. Dziuban, C.D., Hartman, J., Juge, F., Moskal, P.D., Sorg, D., and Trumank, B. (2004). Three ALN modalities: An institutional perspective. In J. Bourne \& J.C. Moore (Eds.), Elements of quality online education: Into the mainstream (pp. 127-148). Needham, MA: Sloan-C.

5. Gram, C.R. (2005). Blended learning systems: Definition, current trends, and future directions. In C.J. Bonk \& C.R. Graham (Eds.), Handbook of blended learning: Global perspectives, local designs (pp. 321). San Francisco, CA: Pfeiffer Publishing.

6. Moore, J.C. (2005). A synthesis of Sloan-C effective practices. Journal of Asynchronous Learning Networks, 9(3), 5-73.

7. Moore, J.C. (2002). Elements of Quality: The Sloan-C framework: Pillar reference manual. Needham, MA: Sloan-C.

8. Russell, T. (2001). The no significant difference phenomenon: A comparative research annotated bibliography on technology for distance education: As reported in 35 research reports, summaries and papers, Montgomery, AL: International Distance Education Certification Center. Retrieved January 28, 2005, from http://www.nosignificantdifference.org.

9. Vignare, K., Geith, C. \& Schiffman, S. Business models for online learning: An exploratory survey. Journal of Asynchronous Learning Networks, 10(2), 53-67.

10. Vignare, K. (2002). Longitudinal success measures for online learning students at the Rochester Institute of Technology. In J. Bourne \& J.C. Moore (Eds.), Elements of quality online education: Into the mainstream (pp. 261-278). Needham, MA: Sloan-C.

11. 11. Vignare, K. (2007). Review of Literature: Blended Learning: Using ALN to Change the Classroom -- Will it Work? In A.G. Piciano \& C.D. Dziuban (Eds.), Blended Learning: Research Perspectives (pp. 37-63). Needham, MA: Sloan-C.

12. Zhao, Y., Lei, J., Lai, B.Y.C., and Tan, H.S. What makes the difference? A practical analysis of research on the effectiveness of distance education. Teachers College Record, 107(8), 1836-1884. 